\title{
ADENOSQUAMOUS CARCINOMA OF THE PENIS
}

Frederico Ramalho Romero, Marília Germanos de Castro, Carlos Ricardo Camargo Garcia, Marjo Deninson Cardenuto Perez

Squamous cell carcinoma (SCC) and its well differentiated variant, verrucous carcinoma (Bushke-Loewenstein tumor), account for the vast majority of penile malignancies. ${ }^{1}$ Adenosquamous carcinoma is an exceptionally rare variation of penile SCC. A review of the English language literature revealed that only 6 cases have been described since the first report of adenosquamous carcinoma of the penis by Jamieson et al in $1986 .{ }^{2-5}$

\section{DESCRIPTION OF THE CASE}

A 70-year-old Japanese descendant presented with a penile lesion that had evolved over 3 years. Initially located at the glans, the lesion slowly progressed to involve the entire length of the penis. On examination, there was an ulcerated, partially necrotic and easily bleeding tumor that totally replaced the glans, foreskin, and penile shaft. Left inguinal adenopathy was present. Blood transfusion was required. Biopsy revealed a pseudoepitheliomatous hyperplastic lesion. Malignancy or cellular atypia were not found. Due to the suggestive malignant aspect of the lesion, a second biopsy was indicated, in which a well-differentiated squamous cell carcinoma was revealed. Total penectomy and perineal uretrostomy was performed. Histopathology showed a 6 × $3 \times 6 \mathrm{~cm}$ tumoral mass extending $1.5 \mathrm{~cm}$ from the distal margin. Microscopic evaluation demonstrated an adenosquamous carcinoma with a predominant squamous component associated with scattered glandular elements (Figures 1A and 1B). Lymphatic invasion and infiltration of the corpora cavernosa were present. Immunohistochemistry showed positivity for high molecular weight cytokeratin (34ßE12) and for carcinoembrionic antigen (CEA) in both components.

One month later, the patient developed swelling and drainage from the left inguinal region. Further diagnostic evaluation revealed no distant metastasis. After proper treatment with antibiotics, the patient underwent bilateral inguinal lymphadenectomy. Due to the presence of positive

Santa Casa de Misericórdia de São Paulo, São Paulo, SP/Brazil Email: frederico.romero@gmail.com lymph nodes on frozen-section analysis of deep inguinal dissection, the patient also underwent pelvic lymph node dissection. Metastatic adenosquamous carcinoma was present in 9 out of 17 lymph nodes on the left side and none of the 21 lymph nodes on the right side. The final pathological stage was T2N3M0. The clinical course was uneventful, and the patient shows no evidence of disease after 5 years of follow-up.

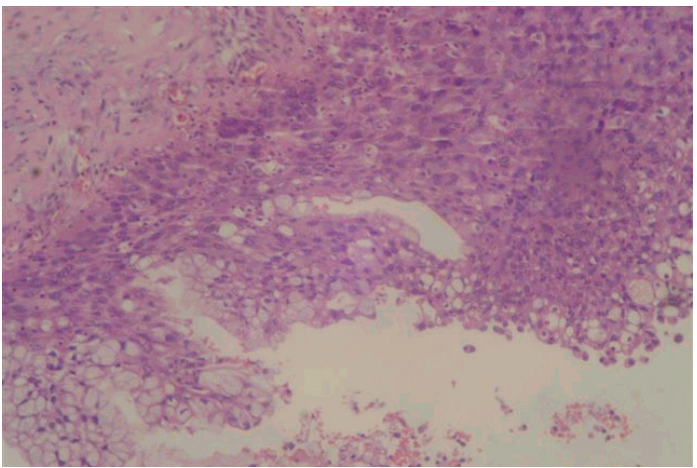

Figure 1A - Well-differentiated squamous cell carcinoma associated with nests of large cells with abundant basophilic cytoplasm and basally located nuclei, tending to assume a glandular arrangement (hematoxylin and eosin; original magnification, 100x).

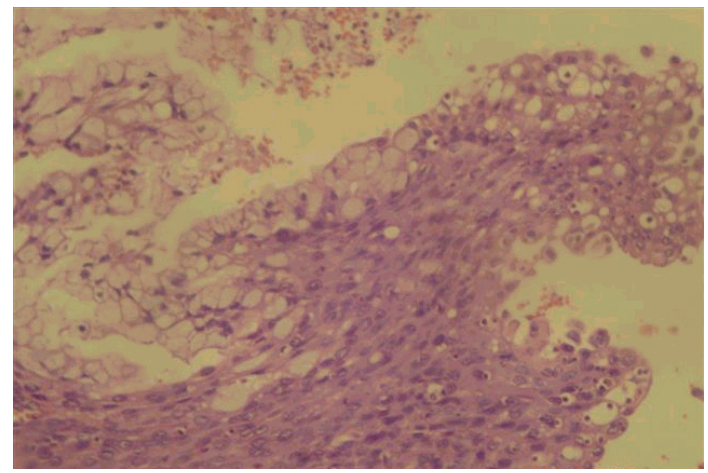

Figure 1B - Higher magnification (hematoxylin and eosin; original magnification, 400x).

\section{DISCUSSION}

Adenosquamous carcinoma is a common malignant tumor of the salivary glands that can also develop from the skin, esophagus, lacrimal ducts, lung, upper respiratory 
Table 1 - Reported cases of adenosquamous carcinomas of the penis

\begin{tabular}{llllll}
\hline References & Year & Patient age & Lymph node metastasis & Treatment & Outcome \\
\hline Jamieson et $\mathrm{al}^{2}$ & 1986 & 50 & No & Radiotherapy & Local recurrence after 2 years \\
Cubilla et al $^{3}$ & 1996 & 74 & No & Total penectomy & No evidence of disease at 12 months \\
& & 72 & Not reported & Total penectomy & Not reported \\
& 37 & Yes & Partial penectomy & No evidence of disease at 8.5 years \\
Masera et al $^{4}$ & 1997 & 30 & Yes & Partial penectomy & Died of tumor at 5 months \\
Lam and Chan & 1999 & 50 & Not reported & Not reported & Not reported \\
Present case & $\mathbf{2 0 0 6}$ & $\mathbf{7 0}$ & Yes & Total penectomy & No evidence of disease at 5 years \\
\hline
\end{tabular}

tract, pancreas, prostate, and thyroid. Rarely, it may occur in the penis. ${ }^{2-5}$

The squamous epithelium of penile skin is the site of origin of most primary penile tumors. ${ }^{1}$ Adenosquamous carcinoma appears to have a bimodal origin, from periurethral mucin-producing cells near the urethral meatus and from the epithelial squamous surface of the glans. ${ }^{3}$

The most important consideration in the differential diagnosis of adenosquamous carcinoma is mucoepidermoid carcinoma. ${ }^{6,7,8}$ Both types of carcinoma present glandular elements, but in adenosquamous carcinoma, the squamous component predominates and there is a true glandular differentiation. ${ }^{7,8}$ In many instances, the terms "adenosquamous" and "mucoepidermoid carcinoma" have been used as synonyms. ${ }^{5,8}$ However, these tumors may have different clinical courses and prognoses. ${ }^{7,8}$ A poor prognosis has been attributed to both variants ${ }^{7,8}$ but, similarly to skin cancer, adenosquamous carcinoma appears to have a more aggressive course ${ }^{8}$ (Table 1). Other tumors that are considerations in the differential diagnosis are adenoid or pseudoglandular SCC, urethral carcinomas, and metastatic lesions to the penis. ${ }^{3}$ Immunohistochemistry may help in the differentiation, as stains for $34 \beta E 12$ and CEA react positively in the squamous and glandular components of both adenosquamous and mucoepidermoid carcinomas, but not in pure squamous cell carcinomas or adenocarcinomas..$^{3,7,8}$

Hyperplastic lesions with no, or minimal, atypia are frequently found in association with differentiated penile carcinomas and may represent difficult diagnostic problems in biopsy materials, such as that in this reported case. A further limitation of biopsy in the diagnosis of mixed tumors is that it may show only 1 of the 2 components. ${ }^{9}$ In the near future, the use of molecular markers will be helpful to determine the neoplastic nature of these lesions.

Surgical excision of the tumor with clear margins is the mainstay of primary therapy for all invasive carcinomas of the penis. ${ }^{1}$ The surgical procedures used have ranged from local excision to total penectomy. Although radiotherapy has been used with success in selected cases of $\mathrm{SCC},{ }^{1}$ it is probably not indicated for adenosquamous carcinoma due to the relative radioresistance of the glandular elements. ${ }^{2}$ To date, chemotherapy has been initiated in only 1 case, ${ }^{4}$ but the patient died within 2 weeks from septic complications.

There is very little follow-up data available, and only 1 reported patient was followed for more than 5 years. ${ }^{3}$ In other primary sites, adenosquamous carcinoma appears to have an indolent course and good prognosis. Further longterm studies are necessary before the prognosis of penile adenosquamous carcinoma can be defined.

\section{REFERENCES}

1. Micali G, Nasca MR, Innocenzi D, Schwartz RA. Invasive penile carcinoma: a review. Dermatol Surg. 2004;30:311-20.

2. Jamieson NV, Bullock KN, Barker THW. Adenosquamous carcinoma of the penis associated with balanitis xerotica obliterans. Br J Urol. 1986;58:730-1.

3. Cubilla AL, Ayala MT, Barreto JE, Bellasai JG, Noel JC. Surface adenosquamous carcinoma of the penis: a report of three cases. Am J Surg Pathol. 1996;20:156-60.

4. Massera A, Ovcak Z, Volavsek M, Bracko M. Adenosquamous carcinoma of the penis. J Urol. 1997;157:2261.

5. Lam KY, Chan KW. Molecular pathology and clinicopathologic features of penile tumors. Arch Pathol Lab Med. 1999;123:895-904.
6. Shrikhande SS, Sirsat MV. Muco-epidermoid carcinoma of the penis: report of an unusual case. Br J Urol. 1974;46:233-5.

7. Layfield LJ, Liu K. Mucoepidermoid carcinoma arising in the glans penis. Arch Pathol Lab Med. 2000;124:148-51.

8. Froehner M, Schöbl R, Wirth MP. Mucoepidermoid penile carcioma: clinical, histologic, and immunohistochemical characterization of an uncommon neoplasm. Urology. 2000;56:154xix-154xxi.

9. Velazquez EF, Barreto JE, Rodriguez I, Piris A, Cubilla AL. Limitations in the interpretation of biopsies in patients with penile squamous cell carcinoma. Int J Surg Pathol. 2004;12:139-46. 